\title{
Treatment of C.I. Reactive Blue-21 effluent by microcrystalline cellulose grafted with APTES: kinetics, isotherm and thermodynamic study
}

\author{
Ravindra D. Kale*, Tejasvi Potdar and Vikrant Gorade
}

\begin{abstract}
The adsorption removal of C.I Reactive Blue 21 (RB-21) dye from aqueous solution by commercial MCC was successfully modified with aminopropyltriethoxysilane. The various physiochemical attributes like initial dye concentration, contact time, solution $\mathrm{pH}$, adsorbent dose and temperature were evaluated. The surface modification was characterised and confirmed with specific surface area analyser using Brunauer-Emmett-Teller, Fourier Transform Infrared Spectroscopy, Scanning Electron Microscopy, Energy Dispersive Spectrometer and X-ray diffraction. The adsorption kinetics, isotherms, and thermodynamics were explored. The Langmuir, Frendlich and Redlich-Perterson isotherm models were studied with the Langmuir adsorption isotherm model showing the best fit with the adsorption capacity of $30 \mathrm{mg} \mathrm{g}^{-1}$ at $323 \mathrm{~K}$. The kinetic data was considered using pseudo-first-order and pseudo-second-order. The results indicated that the pseudo-second-order model was preferred with good correlation. The thermodynamic attributes like changes in standard enthalpy, standard entropy and standard Gibbs free energy were assessed at different operating temperatures. Hence, current research work shows efficient removal of RB-21 dye from effluent solution by modified microcrystalline cellulose.
\end{abstract}

Keywords: RB-21, Modified microcrystalline cellulose, Adsorption, Thermodynamic, Isotherm, Kinetics

\section{Introduction}

Dyes are organic aromatic compound possessing intense color and generating considerable amount of colored waste water and are highly toxic that contribute noteworthy contamination of aquatic ecosystem. Moreover, they actively absorbs solar energy which reduces the intensity of solar light absorbed by the water plants, and create serious threat to aquatic organisms [1-3]. Reactive dyes constitute a major textile wastewater; they are highly soluble in water and the most persistent dye. Reactive dyes are anionic dyes that comparatively require easy dyeing process and find major application for dyeing cellulose fibers like cotton, rayon, silk, wool and leather. Reactive dyes are considerably used in textile industry, essentially due to the ability of their reactive groups to attach on textile fibers by covalent bond formation [4]. C.I Reactive Blue 21 (RB-21) is difficult to decompose due to its

\footnotetext{
* Correspondence: rd.kale@ictmumbai.edu.in

Department of Fibres and Textile Processing Technology, Institute of Chemical Technology, Mumbai 400019, India
}

stable aromatic structure. Thus, the aromatic complex structure of RB-21 dye is tough to biodegrade. The release of this dye into river streams from various textile industries may cause acute problems because of their toxicity, mutagenicity, and non-biodegradability and are detrimental to aesthetic value of the environment [5].

Dye removal from effluent was extensively studied using diverse physical-chemical process that involve methods such as coagulation, flocculation [6], ozonation [7], aerobic-anaerobic treatment [8], and cation exchange membranes [9], but all suffer from one and more limitations, as most treatments are expensive that cause significant problems by the use of harsh type of chemicals and involve tedious process. In contrast with various treatment processes, adsorption is economic and highly efficient method for removal of color from dye wastewater that improves the purity of water resources. Adsorption process involving activated charcoal is the highest reliable adsorbent however its high price restricts its wide application. In this regards, the major

(c) The Author(s). 2019 Open Access This article is distributed under the terms of the Creative Commons Attribution 4.0 International License (http://creativecommons.org/licenses/by/4.0/), which permits unrestricted use, distribution, and 
shift has occurred towards the use of low cost naturally occurring waste materials. Therefore, significant focuses of researchers have directed to explore new promising alternatives for removal of dyes from wastewater [10].

Cellulose, abundantly found in nature has gained noticeable attention due to its low cost, economic execution, wide availability; also they are renewable and sustainable material. Accordingly, cellulose as well as cellulose-based waste products [11] has been used including saw-dust [12], rice-husk [13], and orange peel [14] for the removal of colored matter from dye wastewater. Precisely, cellulose is greatly marked as an efficient adsorbent and the structure has been chemically modified, which stimulates the adsorption capacity of dye from wastewater effluents [15]. A surface modification of cellulose includes attachment of alkaline centre in the cellulose structure using distinct nitrogen precursors (e.g., ethylenediamine [16], 2- aminomethylpyridine [17], cationic and anionic forms of cellulose were synthesized by presenting quaternary ammonium and carboxyl groups to remove ciprofloxacin from aqueous media [18]. Modification of cellulose by grafting a quaternary ammonium salt was used for removal of amoxicillin from aqueous solution [19]. The phosphate derivatives of cellulose have been employed in the treatment from the acetaminophen saturated water [20]. Adsorption capacities of cellulose have been considerably enhanced after treatment with amines such as 3-chloro-2-hydroxypropyltriethylammonium chloride [21], triethylamine [22], and tetramethylethylenediamine [23]. To date, there has been no information in representing microcrystalline cellulose (MCC) as adsorbent grafted with aminopropyltriethoxysilane (APTES) for the removal of RB-21 dye from aqueous solution. In the current protocol, we herein report the chemical modification of MCC by linking of amino group to the backbone of MCC using APTES. The modified MCC (MMCC) was characterized by Brunauer-Emmett-Teller (BET), Fourier Transform Infrared Spectroscopy (FTIR), Scanning Electron Microscopy (SEM), Energy Dispersive Spectrometer (EDS) and $\mathrm{X}$-ray diffraction (XRD). The adsorption efficiency of the product was evaluated by employing optimization studies using different variables, such as initial dye concentration, contact time, solution $\mathrm{pH}$, adsorbent dose and temperature. Moreover, the results were evaluated via different isotherm, kinetic and thermodynamics models.

\section{Materials and methods Materials}

RB-21 was procured from Colourtex Industries Pvt. (India). The material used in this work was commercial MCC having size $13 \mu \mathrm{m}$ purchased from Rettenmaier India Pvt. (India). APTES was procured from Rishichem Distributor Pvt. (India). The $\mathrm{pH}$ was adjusted to the desired value by adding $0.1 \mathrm{M}$ acetic acid or $0.1 \mathrm{M}$ sodium hydroxide. Ethanol, soda ash, glauber's salt, acetic acid, and sodium hydroxide were bought from S D Fine-Chem Pvt. (India). All the experiments were carried out using distilled water.

\section{Surface treatment of MCC}

$0.15 \mathrm{~mL}$ of APTES (1\% weight of MCC) was dissolved in a mixture of $80 / 20(\mathrm{v} / \mathrm{v})$ ethanol/water solvent, and was stirred using magnetic stirrer for $1 \mathrm{~h}$ which became hydrolysed to form reactive silanol groups. $15 \mathrm{~g}$ of MCC was added in this solvent mixture and further stirred for $2 \mathrm{~h}$. Ethanol was removed by evaporation by exposing it to ambient temperature for $24 \mathrm{~h}$. This grafted MCC was subsequently kept in the oven at $393 \mathrm{~K}$ for $2 \mathrm{~h}$ for curing followed by thorough washing with water to remove the last traces of ethanol then drying at room temperature. The MMCC powder was used for further study.

\section{Mechanism of MCC}

The hydrolysis of three labile groups occurs giving rise to three hydroxyl groups. Later, addition of water and alcohol favours a high degree of polymerization and stabilized monomeric silanol is formed. The silanol forms hydrogen bond with the $\mathrm{OH}$ groups of the MCC. Finally, during curing, formation of covalent bonds with the MCC proceeds with simultaneous water loss [24]. The reaction mechanism of surface modification of MCC is systematically represented below.

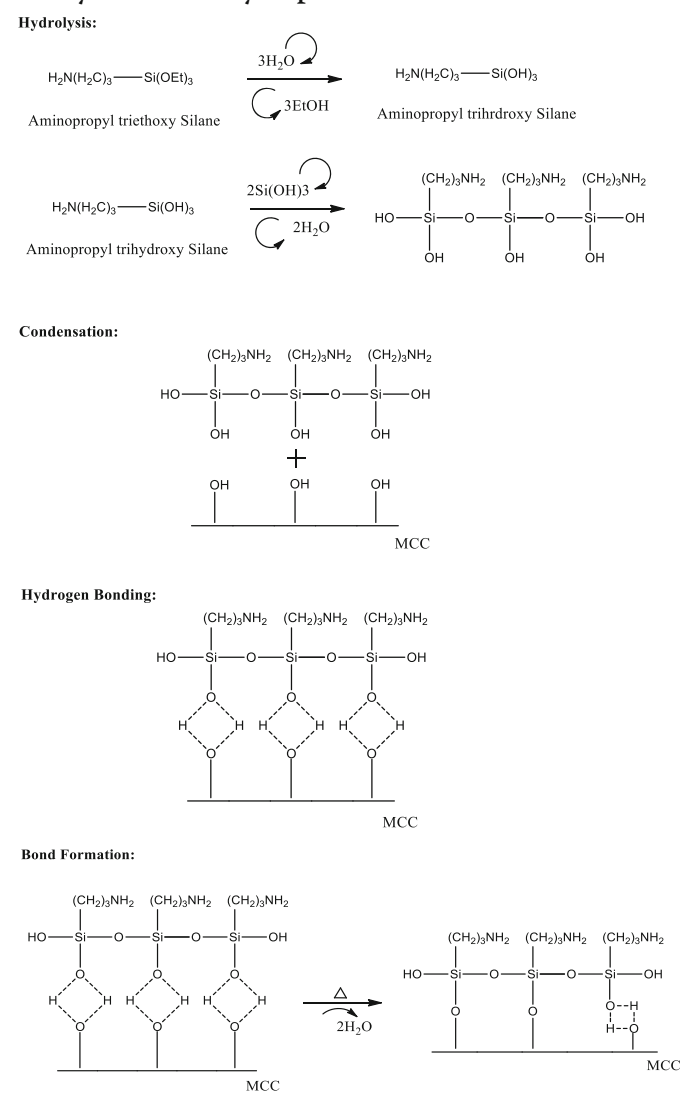




\section{Adsorption studies}

Batch adsorption trails were performed using virgin MCC to investigate various parameters but the results of the study indicated that MCC was not suitable adsorbent for removal of dye. Apart long equilibrium time, the efficiency was not satisfactory. Hence, dye removal experiments with MMCC were carried out as batch mode in $100 \mathrm{~mL}$ Erlenmeyer flasks in a shaker bath containing RSB-12. Various parameters such as $\mathrm{pH}$ ( 2 to 12$)$, initial dye concentration (40 to $120 \mathrm{mg} \mathrm{L}^{-1}$ ), temperature (303 to $323 \mathrm{~K}$ ), and contact time (0-60 min) were investigated. Desired amount of absorbent was merged with $50 \mathrm{~mL}$ of aqueous dye solution in 12 sets of Erlenmeyer flasks. Then each flask was enclosed with glass stopper and the flask was properly fitted from the base of the shaker bath at different controlled temperatures $(303,313,323 \mathrm{~K})$. The mixture was agitated at $150 \mathrm{rpm}$ until equilibrium was attained. At the predetermined time, a small amount of supernatant solution was taken out by using pipette and centrifuged at $3000 \mathrm{rpm}$ for $15 \mathrm{~min}$. The colour of the supernatant solution was analysed at $622 \mathrm{~nm}$ using a UV-Vis spectrophotometer (UV-Vis1800, Shimadzu, Japan). The percentage decolourisation of the dye solution after treatment with MMCC was designed as follows,

$$
\% \text { Removal }=\frac{\left(C_{i}-C_{e}\right)}{C_{i}} \times 100
$$

where, $C_{i}$ is the initial dye concentration before sorption in $\mathrm{mg} \mathrm{L}^{-1}, \mathrm{C}_{\mathrm{e}}$ is the equilibrium concentration of dye after sorption in $\mathrm{mg} \mathrm{L}^{-1}$.

\section{Variation in percentage of silane}

To study the effect of silane, the APTES percentage was varied as $1,3,5$ and $6 \%$ on the weight of MCC. It was dissolved in the mixture of $80 / 20(\mathrm{v} / \mathrm{v})$ ethanol/water and stirred using magnetic stirrer for $1 \mathrm{~h}$ to hydrolyse and form reactive silanol groups. After $1 \mathrm{~h}, 15 \mathrm{~g}$ of MCC was added in each beaker and further stirred for $2 \mathrm{~h}$. Each beaker was poured onto petri dish to evaporate ethanol. After complete evaporation of ethanol it was placed in oven at $393 \mathrm{~K}$ for period of $2 \mathrm{~h}$. These powders were used for further batch study.

\section{Reusability studies}

Desorption experiment were studied to analyse the reusability of the adsorbent. After the completion of experiment, the used adsorbent was centrifuged to separate the adsorbent and dye solution. Further, it was filtered through Whatman filter paper and rinsed mildly for several times with distilled water and further with acetone to get rid of some type of dye attached to the adsorbent particles. The washed adsorbent was then rinsed at room temperature before using for the next run of experiments.

\section{Characterization of the MMCC}

Following characterisation was carried out to understand the changes taking place after modification.

\section{Specific surface area}

The specific surface area of MCC and MMCC was studied through Nitrogen atmosphere adsorption at $77 \mathrm{~K}$ using BET Sorptometer (PMI, USA).

\section{FTIR}

The FT-IR-8400S manufactured by Shimadzu (Japan) with a scanning resolution of $4 \mathrm{~cm}^{-1}$ was used to detect the IR spectra of samples. It was observed in the range of $4000-800 \mathrm{~cm}^{-1}$.

\section{Morphology analysis}

The powdered adsorbent was fixed on an aluminium holder and sputtered with gold-palladium alloy in a sputter coater and were characterised by SEM (Philips XL-30, Netherlands). The surface structure of the MCC before and after silane modification was analysed by EDS (JEOL JSM-638OLA, Germany). The morphology of different crystalline phases was identified by XRD and was recorded on XRD-6100 Simadzu (Japan) at $40 \mathrm{kV}$ and $30 \mathrm{~mA}$. The diffraction pattern was obtained in equal reflection mode with $\mathrm{Cu} K \alpha$ radiation $(\lambda=1.5405 \AA)$. The angular range $(2 \theta)$ was obtained from 5 to $30^{\circ}$ and the measurements were brought together having a sampling pitch of $0.02^{\circ}$ employing uninterrupted mode of scanning, at the rate of $2^{\circ} \min ^{-1}$. By using Eq. (2) Segal method, crystallinity index (ICr) of the adsorbents was estimated.

$$
\% \mathrm{ICr}=\left[1-\left(\frac{\mathrm{I}_{a m}}{\mathrm{I}_{002}}\right)\right] \times 100
$$

where $I_{a m}$ is the intensity of the background scatter measured at $2 \theta$ angle array in the middle of 16 and $20^{\circ}$, when the intensity is least, and $\mathrm{I}_{002}$ gives extreme intensity of diffraction from the 002 plane at a $2 \theta$ angle in the middle of 22 and $24^{\circ}$.

\section{Statistical analysis}

With the purpose to figure out statistical parameters, single-factor analysis of variance with excels was incorporated. Statistical analysis is a decisive mode to explicate the data. All the experiments were brought about in triplet and the outcome effects is numerated as mean \pm SD. $P$-value lower than 0.5 are statistically significant. 


\section{Results and discussion Characterization BET analysis}

Pore size are classified as micropores $\left(<20 \mathrm{~A}^{\circ}\right)$, mesopores $\left(20-500 \mathrm{~A}^{\circ}\right)$ and macropores $\left(>500 \mathrm{~A}^{\circ}\right)$. The BET surface area was found to be 17 and $43 \mathrm{~m}^{2} \mathrm{~g}^{-1}$ for $\mathrm{MCC}$ and MMCC, respectively. The isotherm observed was of Type IV mesoporous surface showing a linear increase of adsorbed-desorbed volume at low pressure and shows limited uptake at a relative pressure and also exhibited hysteresis loop which indicated the mesoporous nature of the prepared material [25]. In addition, the total pore volume and average pore size of MCC were $0.021 \mathrm{cc} \mathrm{g}^{-1}$ and $51.17 \mathrm{~A}^{\circ}$ and for MMCC, they were $0.049 \mathrm{cc} \mathrm{g}^{-1}$ and $46.50 \mathrm{~A}^{\circ}$ indicating that material is mesoporous in nature.

\section{FTIR}

Figure 1 clearly depicts the FTIR spectra of MCC and MMCC. As seen from Fig. 1, the band at $3346 \mathrm{~cm}^{-1}$ was observed for MCC that features $\mathrm{O}-\mathrm{H}$ stretching vibration of hydroxyl group of cellulose and the peak at 2885 $\mathrm{cm}^{-1}$ corresponds to $\mathrm{C}-\mathrm{H}$ stretching region. New absorption peak at 1560 and $1481 \mathrm{~cm}^{-1}$ was noted in the spectrum of MMCC which were due to the N-H bending vibration of primary amine proving the successful grafting of the APTES onto the MCC. The peaks at $3346 \mathrm{~cm}^{-1}$ responsible for $\mathrm{O}-\mathrm{H}$ bond were subdued because of the reduction in the number of this functional group [26]. The strong absorption peak around 1249,1034 and $700 \mathrm{~cm}^{-1}$ regions is allocated to the $\mathrm{Si}-\mathrm{O}-\mathrm{Si}$ and $\mathrm{Si}-\mathrm{O}-\mathrm{C}_{\text {cellulose }}$ [27]. The intensity of the peak at $1034 \mathrm{~cm}^{-1}$, is an overlay of $\mathrm{Si}-\mathrm{O}-\mathrm{Si}$ band and the $\mathrm{C}-\mathrm{O}$ stretching of cellulose, which increases after treatment of silane, providing clear proof of silane reaction [28].

\section{SEM and EDS}

SEM photographs (at 2000x magnification) of MCC and MMCC powder are illustrated in Fig. $2 a$ and $b$ whereas elemental analysis was carried out by the EDS analysis of MCC and MMCC powder as represented in Fig. 2c and d. Figure 2a showed virgin MCC which has irregular shape, smooth surface and compact rod-like aggregates. Figure $2 \mathrm{~b}$ showed MMCC powder becoming rougher and porous after modification process. The porous nature was suitable for the RB-21 dye adsorption. For EDS analysis, it was found that in Fig. 2c, MCC contains presence of C (63.3\%) and $\mathrm{O}(36.8 \%)$. Figure $2 \mathrm{~d}$ clearly shows MMCC which contains C (55.1\%), O (2.6\%) and Si (12.3\%). Si peak provides evidence for the presence of APTES on the MCC skeleton [29].

\section{$X R D$}

MCC powder and MMCC were crystallographically characterized by means of XRD. From Fig. 3, the peaks at $2 \theta=14.7,16.4$ and 22.2 corresponds to the crystal structure of MCC, typically that of cellulose-I structure only. The crystallinity of MCC and MMCC was found to be 76.7 and $75.6 \%$ respectively. From these values it is verified that the crystallinity of MCC remains same after modification and had no effect on adsorption study.

\section{Effect of silane percentage}

Percentage removal of RB-21 was studied using $100 \mathrm{mg}$ $\mathrm{L}^{-1}$ of the dye at $\mathrm{pH} 3$ and $0.2 \mathrm{~g}$ of adsorbent for $60 \mathrm{~min}$ by varying the percentage of silane grafted on MCC. Removal of RB-21 was carried out with unmodified MCC powder, but results obtained were very poor. From the trial studies as discussed in section 2.2.3, it is clear that no difference in the removal percentage of the dye beyond $5 \%$. Hence $5 \%$ of silane was selected for removal of RB-21 in the next steps of this study.

\section{Effect of initial solution $\mathrm{pH}$}

The solution $\mathrm{pH}$ is a pre-eminent parameter for decolourisation, in determining the surface charge of adsorbent, by amending the chemical stability of the ionic groups, consequently effecting electrostatic interaction [30]. In order to investigate optimum $\mathrm{pH}$ value, adsorption experiments were performed at different $\mathrm{pH}$ range (2-12). Figure $4 \mathrm{a}$ depicts that dye sorption decreases with increase in $\mathrm{pH}$ value with satisfactory adsorption of RB-21 from $\mathrm{pH} 2$ to 4 , in which most of the amine group $\left(-\mathrm{NH}_{2}\right)$ are protonated, which is necessary for the attraction of anionic sulfonic groups of the dye molecule. At higher $\mathrm{pH}$, free hydroxyl groups $\left(\mathrm{OH}^{-}\right)$in solution are in competition with anionic sulfonic groups of RB-21 for the adsorption sites of the MMCC thereby decreasing adsorption sites for the dye molecule. Thus, lower $\mathrm{pH}$ values ( $\mathrm{pH}$ 2) for the adsorption of RB-21 dye was considered optimum and used for further experiment [31].

\section{Zero-point charge (ZPC) of adsorbent}

The effect of $\mathrm{pH}$ on the dye removal can be explained by studying the zeta potential values of adsorbent at various $\mathrm{pHs}$ [32]. To determine the $\mathrm{pH}_{\mathrm{zpc}}, 50 \mathrm{~mL}$ of $0.01 \mathrm{M} \mathrm{NaCl}$ solution were added in various Erlenmeyer flasks. To each flask, $0.2 \mathrm{~g}$ of adsorbent was added. Further, the $\mathrm{pH}$ values of the above solution were regulated in range of 2-12 by adding either $0.1 \mathrm{M} \mathrm{HCl}$ or $0.1 \mathrm{M}$ $\mathrm{NaOH}$ solution. Now, each flask was preserved for $48 \mathrm{~h}$ and the final $\mathrm{pH}$ was enumerated. The graphs were plotted amongst $\mathrm{pH}_{\text {final }}$ versus $\mathrm{pH}_{\text {initial }}$ and the point of interaction of the curve of $\mathrm{pH}_{\text {final }}$ versus $\mathrm{pH}_{\text {initial }}$ was reported as $\mathrm{pH}_{\mathrm{zpc}}$. As seen from the Fig. 4b, $\mathrm{pH}_{\mathrm{zpc}}$ of 


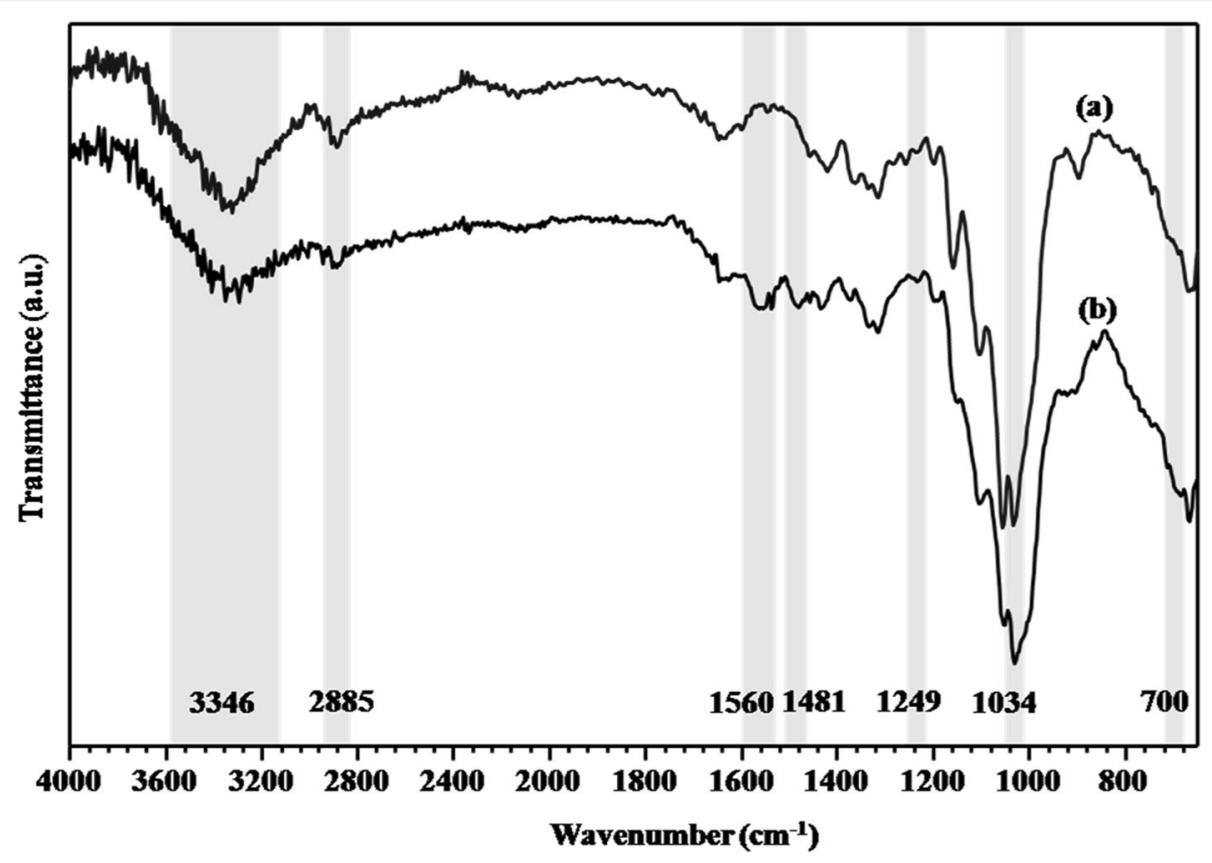

Fig. 1 FTIR Spectrum of (a) MCC and (b) MMCC
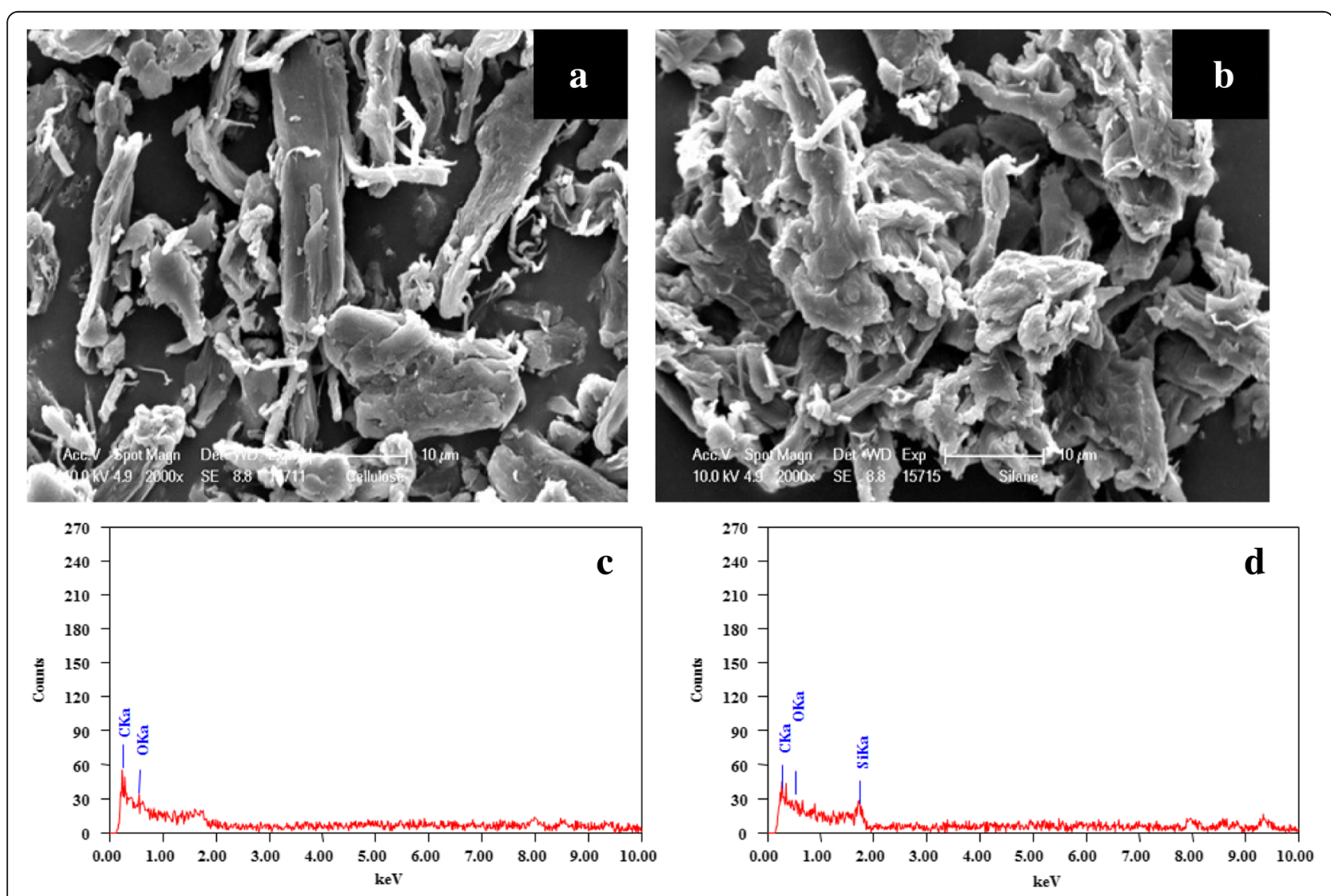

Fig. 2 SEM images of (a) MCC powder at magnification of 2000 X (b) MMCC powder at magnification of 2000 X. EDS image of (c) MCC powder and (d) MMCC powder 


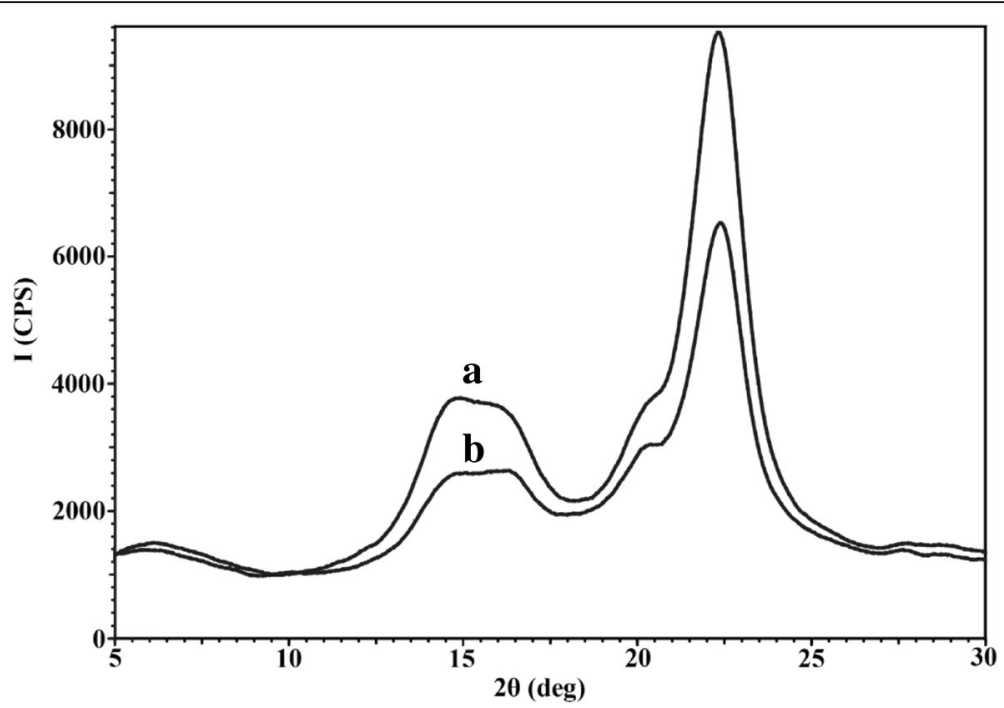

Fig. 3 XRD patterns of (a) MCC powder and (b) MMCC powder

adsorbent was found to be 5.6. At $\mathrm{pHs}$ below $\mathrm{pH}_{\mathrm{zpc}}$, the reactant surfaces become positively charged which attract anions present in the solution. The exterior layer of adsorbent is negatively charged at $\mathrm{pHs}$ higher than $\mathrm{pH}_{\mathrm{zpc}}$, thus attracting cations. In this study, lower $\mathrm{pH}$ is suitable for removal of dye, due to electrostatic attraction between positively charged sites and negatively charged dye ions [33].

\section{Effect of initial dye concentration and contact time}

The effect of initial dye concentration and contact time on the adsorption of RB-21 dye onto the adsorbent is shown in Fig. 4c (0.25 g of MMCC at $\mathrm{pH}$ 2). Initial dye concentration is inversely proportional to percentage of dye removal as certain fix amount of dye is adsorbed for given mass of adsorbent. When concentration of dye is higher, the removal efficiency will be lower. This is because when concentration decreases, there will be more active sites for adsorption. By increasing the concentration there will be less active sites for adsorption. As a result, when initial concentration increases, it exhausts the adsorption process sharply. The equilibrium adsorption capacity increased from 8 to $20 \mathrm{mg} \mathrm{g}^{-1}$ with the increase of the initial dye concentration from 40 to $120 \mathrm{mg} \mathrm{L}^{-1}$. It is observed that dye concentration acts as a driving force against the resistance for dye transport from the solution to the adsorbent. It seems that the amount of dye adsorbed increases with increase in contact time and then attains equilibrium state. At first stage, adsorption process was prompt and consequently the adsorption rate reduced for all the initial concentrations, slowly reaching equilibrium. It was found that for adsorption of $100 \mathrm{mg} \mathrm{L}^{-1}$ of dye concentration, it took $50 \mathrm{~min}$ for equilibrium to obtain contact time. This reading was taken into consideration for further experimentation to verify that equilibrium and dye adsorption is achieved [34].

\section{Effect of adsorbent doses}

Various trails of experiments for different adsorbent doses were conducted using initial concentration as $100 \mathrm{mg} \mathrm{L}^{-1}$ for $50 \mathrm{~min}$ keeping the volume unchanged, i.e., $50 \mathrm{~mL}$. The results of experiment show that the quantity of active sites on the exterior increases with increase in dosage i.e. they are directly proportional as shown in Fig. 4d. As a result, when the dosages were increased, there were more active sites which caused higher percentage removal of dye. Thus the dye removal efficiency enhanced drastically from 70 to $94 \%$ with increase in the adsorbent dosage as shown in Fig. $4 \mathrm{~d}$. Further experiments with adsorbent beyond $0.25 \mathrm{~g}$ showed that there was no marginal or specific change in the results. It was observed that for $0.25 \mathrm{~g}$ of adsorbent, maximum efficiency of removal was $94 \%$. Thus, it can be considered that $0.25 \mathrm{~g}$ is the optimum amount of adsorbent for decolourisation.

\section{Reusability study}

In order to make the method economical, the reusability of the adsorbent was explored by using the recovered adsorbent for successive cycles under optimized reaction conditions ( $\mathrm{pH} 2$, dye concentration $100 \mathrm{mg} \mathrm{L}^{-1}, 0.25 \mathrm{~g}$ of adsorbent and $50 \mathrm{~min}$ ). After completion of each cycle, the used adsorbent particles were separated from dye solution through filtration using Whatman filter paper and washed several times with distilled water and further washed with acetone to eliminate the residues of 



Fig. 4 Effect of operating conditions on \% decolourisation of RB-21 on MMCC. (a) Effect of pH (Initial concentration-100 mg L - $^{-1}$, Adsorbent doage$0.2 \mathrm{~g}$, Contact time- $60 \mathrm{~min}$, Agitation rate-200 rpm, Volume-50 mL). (b) Influence of initial pH and final pH of point of zero charge ( $\mathrm{pH}_{\mathrm{zpc}}$ ) of MMCC. (c) Effect of initial dye concentration and contact time ( $\mathrm{pH}-2$, Adsorbent doage- $0.2 \mathrm{~g}$, Contact time-60 min, Agitation rate-200 rpm, Volume-50 mL). (d) Effect of adsorbent dose (Initial concentration-100 mg L ${ }^{-1}, \mathrm{pH}-2$, Contact time-60 min, Agitation rate-200 rpm, Volume-50 mL). (e) Reusability study of adsorbent (pH-2, Adsorbent dosage- $0.25 \mathrm{~g}$, Dye concentration- $100 \mathrm{mg} \mathrm{L}{ }^{-1}$, Contact time- $50 \mathrm{~min}$, Agitation rate-200 rpm, Volume-50 mL). (f) Effect of temperature (Initial concentration-100 mg L ${ }^{-1}$, Adsorbent doage- $0.25 \mathrm{~g}$, Contact time-60 min, Agitation rate-200 rpm, Volume-50 mL)

dye molecule, dried at room temperature before reuse. As seen in Fig. 4e, the dye removal efficiency was 87, 80, 74 and $71 \%$ from cycle 1 to 4 . Comparatively lower adsorption/desorption of dye conveys that chemisorption might be the main condition of dye removal.

\section{Preparation of waste dyeing water}

Other important study was borne out as in to simulate the actual dye effluent; cotton fabric was dyed with the RB-21 dye in the open bath. Material to liquor ratio of $1: 30$ and $2 \%$ of dye solution was used on the weight of fabric basis. Dyeing was started at room temperature and the temperature was gradually raised to $65^{\circ} \mathrm{C} .80 \mathrm{~g} \mathrm{~L}^{-1}$ of glauber salt was added after reaching $65^{\circ} \mathrm{C}$ and the dyeing was continued for $30 \mathrm{~min}$. Later $20 \mathrm{~g}$ soda ash was added and dyeing lasted for another $60 \mathrm{~min}$. The spent dye liquor after dyeing was collected and treated with modified adsorbent. About $0.25 \mathrm{~g}$ of adsorbent was added into $50 \mathrm{~mL}$ of the wastewater and stirred at $150 \mathrm{rpm}$ for $60 \mathrm{~min}$. After that, the solution was centrifuged for $15 \mathrm{~min}$ at $3000 \mathrm{rpm}$ and supernatant solution was analysed at $622 \mathrm{~nm}$ using UV-Vis spectrophotometer and dye removal was found to be $60 \%$. Thus it was observed that less adsorption takes place in the presence of salt which covered adsorbent surface, resulting from competition between negatively charged ions of the salt and dye anions for the adsorption sites. The salt anions are smaller in size and have a 
greater surface charge density hence they are more strongly adsorbed.

\section{Effect of temperature on adsorption of RB-21 and thermodynamics studies}

The effect of temperature $(303,313,323 \mathrm{~K})$ on the adsorption was evaluated using an initial dye concentration of $100 \mathrm{mg} \mathrm{L}^{-1}$ with $0.25 \mathrm{~g}$ of adsorbent at $\mathrm{pH}$ 2. Temperature in the adsorption studies is used to predict whether it is an exothermic or endothermic process. Figure $4 \mathrm{f}$ indicates that there is slight improvement of decolourisation with temperature which may be related to an increase in active surface sites as well as larger pores size available for adsorption on adsorbent [35]. The adsorption capacity increased from 23 to $30 \mathrm{mg} \mathrm{g}^{-1}$ with the rise in temperature, indicating that the adsorption process of RB-21 by MMCC was an endothermic in nature.

Thermodynamic study is essential to determine the practicability and spontaneous nature of the adsorption [36]. The adsorption efficiency of an adsorbent depends on the thermodynamic parameters such as changes in standard enthalpy $\left(\Delta \mathrm{H}^{\circ}\right)$, standard entropy $\left(\Delta \mathrm{S}^{\circ}\right)$ and standard Gibbs free energy $\left(\Delta G^{\circ}\right)$ and these values are deliberated from the equations given below,

$$
\Delta G^{\circ}=-R T \ln K_{L}
$$

Following Van't Hoff equation,

$$
\ln K_{L}=\frac{\left(\Delta S^{\circ}\right)}{R}-\frac{\Delta H^{\circ}}{R T}
$$

where $\mathrm{K}_{\mathrm{L}}$ is the Langmuir equilibrium constant, $\mathrm{R}$ is the universal gas constant $\left(8.314 \mathrm{~J} \mathrm{~mol}^{-1} \mathrm{~K}^{-1}\right), \mathrm{T}$ is the temperature (K), $\Delta \mathrm{S}^{\circ}$ is the standard entropy change and $\Delta \mathrm{H}^{\circ}$ is the standard enthalpy change. The $\Delta \mathrm{G}^{\circ}$ values of the adsorption at different temperatures were determined form the equation given below,

$$
\Delta G^{\circ}=\Delta H^{\circ}-T \Delta S^{\circ}
$$

Thermodynamic attributes for the adsorption of RB-21 dye with initial dye concentration of $100 \mathrm{mg}$ $\mathrm{L}^{-1}$ onto $\mathrm{MMCC}$ at distinct temperatures were calculated. The $\Delta \mathrm{G}^{\circ}$ at 303,313 and $323 \mathrm{~K}$ are -16.4 , -15.8 and $-15.3 \mathrm{~kJ} \mathrm{~mol}^{-1}$ respectively. The negative values of $\Delta G^{\circ}$ at all temperatures specify the practicability and spontaneous nature while the positive $\Delta \mathrm{H}^{\circ}$ (33.4 $\left.\mathrm{kJ} \mathrm{mol}^{-1}\right)$ value indicates endothermic nature. The positive nature of $\Delta S^{\circ}$ value $(0.47 \mathrm{~kJ}$ $\mathrm{mol}^{-1}$ ) indicates the increased randomness at adsorbent/adsorbate edge during adsorption of the dye onto the MMCC.

\section{Adsorption isotherms}

The adsorption isotherm is an equilibrium data which expresses the correlation among the amounts of adsorbate adsorbed per unit weight of adsorbent and shows the distribution of adsorbates among the liquid/ solid phases. The equilibrium results for the removal of RB-21 in the present work examination were assessed using Langmuir, Freundlich and Redlich-Peterson isotherm equations as presented in Fig. 5 with the values obtained specified in Table 1 .

\section{Langmuir isotherm}

According to Langmuir isotherm principle, it states that it is the monolayer adsorption assumption which is used to describe adsorption on homogenous surfaces. Thus, when saturation value is reached, there is no further adsorption process. The linear form of Langmuir isotherm can be conveyed as illustrated in Eq. (6)

$$
\frac{C_{e}}{q_{e}}=\left(\frac{1}{q_{\max }}\right) b+\frac{C_{e}}{q_{\max }}
$$

where, $C_{e}$ is the equilibrium concentration of the adsorbate, $\mathrm{q}_{\mathrm{e}}$ is the amount of adsorbate per unit mass of adsorbent, $\mathrm{q}_{\max }$ and $\mathrm{b}$ are Langmuir constants which are related to the adsorption capacity and adsorption energy, respectively. The results from Langmuir model are shown in Table 1 and the correlation coefficients signify the fitness of Langmuir isotherm. The correlation coefficient (0.99) value implies the fittingness of the linear mode of Langmuir model. The superlative monolayer sufficiency $\mathrm{q}_{\max }$ derived from Langmuir model increases with increase in the temperature and the data procured intended that the superior adsorption is consistent to a saturated monolayer of adsorbate molecules on the superficial to adsorbent suggesting endothermic nature of adsorption.

\section{Freundlich isotherm}

For Freundlich isotherm model, exponential distribution of active sites depends upon adsorption on heterogeneous surfaces and as a result of this there is no saturation value for their energies. The Freundlich isotherm model is denoted by Eq. (7)

$$
q_{e}=K_{f} C_{e^{\frac{1}{n}}}
$$

The linear form of the Freundlich isotherm can be expressed as illustrated in Eq. (8) 



Fig. 5 Isotherm plots for adsorption of RB-21 on MMCC (a) Langmuir isotherm (b) Freundlich isotherm and (c) Redlich-Peterson isotherm

$$
\ln q_{e}=\ln K_{f}+\frac{1}{n} \ln C_{e}
$$

where, $K_{f}$ and $n$ are the Freundlich isotherm constants. $\mathrm{K}_{\mathrm{f}}$ is defined as the adsorption capacity, while $1 / \mathrm{n}$ provides estimation of the intensity of adsorption. Values, $n>1$ represent favourable adsorption condition. However, correlation coefficients $\left(R^{2}<0.90\right.$; Table 1$)$ is lower than Langmuir values, which shows that adsorption onto MMCC not following Freundlich isotherm closely.

Table 1 Adsorption isotherm parameters at various temperatures

\begin{tabular}{lllll}
\hline Isotherm & Parameters & \multicolumn{3}{l}{ Temperatures $(\mathrm{K})$} \\
\cline { 3 - 5 } & & 303 & 313 & 323 \\
\hline Langmuir & $\mathrm{q}_{\max }\left(\mathrm{mg} \mathrm{g}^{-1}\right)$ & 23.0 & 28.2 & 30.4 \\
& $\mathrm{~b}\left(\mathrm{~L}^{-1} \mathrm{mg}\right)$ & 0.76 & 0.48 & 0.33 \\
& $\mathrm{R}^{2}$ & 0.99 & 0.99 & 0.99 \\
Freundlich & $\mathrm{K}_{\mathrm{f}}\left(\mathrm{L} \mathrm{mg}^{-1}\right)$ & 10.3 & 10.3 & 10.0 \\
& $\mathrm{n}$ & 0.32 & 0.33 & 0.68 \\
& $\mathrm{R}^{2}$ & 0.91 & 0.94 & 0.98 \\
Redlich-Peterson & $\mathrm{K}_{\mathrm{RP}}$ & 2.32 & 2.32 & 2.30 \\
& $\beta$ & 0.67 & 0.66 & 0.68 \\
& $\mathrm{R}^{2}$ & 0.97 & 0.98 & 0.98 \\
\hline
\end{tabular}

\section{Redlich-Perterson isotherm}

The Redlich-Peterson isotherm model was for the adsorption equilibrium throughout the concentration array and due to the fact that its thoroughness can be functional to either homogeneous or heterogeneous systems. The Redlich-Peterson isotherm model is denoted by Eq. (9)

$$
\ln \left(K_{R P} \frac{C_{e}}{q_{e}}-1\right)=\ln \left(a_{R P}\right)+\beta \ln \left(C_{e}\right)
$$

where, $K_{R P}$ and $a_{R P}$ are the Redlich-Peterson adsorption capacity constant and isotherm constant, respectively with $\beta$ between 1 and 0 . From Table 1 , the $R^{2}>$ 0.98 can be consider as less applicable than the data obtained for other 2 isotherm models, namely Langmuir and Freundlich isotherm models. Hence Redlich-Perterson isotherm model has been ruled out.

The data of the current study indicates that Langmuir isotherm model is the utmost adapted for the fitting of adsorption isotherm of RB-21 dye by MMCC. The maximum adsorption capacity of RB-21 dye was calculated to be $30 \mathrm{mg} \mathrm{L}^{-1}$.

\section{Weber and mores equation}

The quintessential diffusion process of liquid-surface adsorption phenomenon is contemplated on the base that one diffusion endurance is assumed to be predominant 

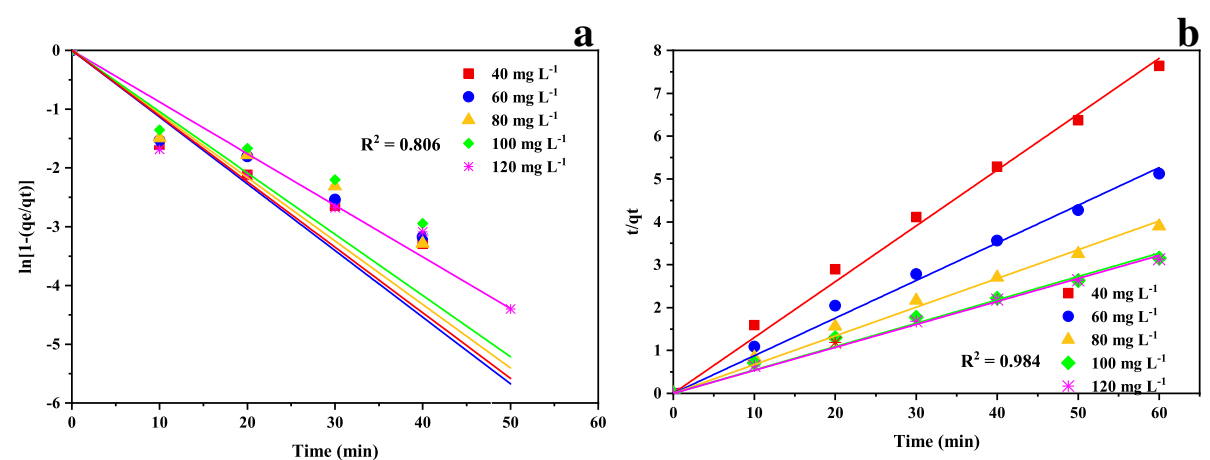

Fig. 6 Kinetic models for (a) pseudo first order for RB-21 on adsorbent for different initial concentration, and (b) pseudo second order for RB-21 on adsorbent for different initial concentration. (Initial concentration-40, 60, 80, 100, $120 \mathrm{mg} \mathrm{L}^{-1}$, Adsorbent doage-0.25 g, Contact time-60 min, Agitation rate-200 rpm, Volume-50 mL)

over other diffusion endurance. The fundamental diffusion resistance for adsorption of MMCC is to be film or intraparticle hindrance depending upon the augment of polymer crosslinking. With the intention to evaluate the impact of film and intraparticle diffusion endurance for adsorption kinetics, the weber mores equation was correlated from Fick's law of adsorbent distributing in spherical adsorbent particle at a relatively less duration of time. This can be employed to determine the correlation between uptake of adsorbent (q), and square root of adsorption as,

$$
q=k t^{\frac{1}{2}}+I
$$

where, $\mathrm{k}$ represents the diffusion rate component. The value derived from the intercept (I) is analogous to the probable thickness of the film borderland layer. If the primary part of Weber- Mores plot is a straight line graph passing through the origin, it specifies that an adsorption process is solely induced by intraparticle diffusion. Whereas, the intercept on y axis with negative value signifies the impact of apparent film diffusion obstruction. The literature data have revealed positive intercept for adsorption on carbonaceous matter that signifies instantaneous uptake of initial adsorbate [37].

\section{Kinetic modelling}

With the intention to evaluate the adsorption mechanism like mass transfer or diffusion control and chemical reaction it is effective to ascertain the kinetic model. Hence, pseudo-first-order and pseudo-second-order models were evaluated to examine and formulate the adsorption kinetics of the dye [38].

\section{Pseudo-first order model}

The pseudo first order model was studied to calculate the rate constant of adsorption $\mathrm{k}_{1}$ from Eq. (11) and integrating of the Eq. (11) at the perimeter of $\mathrm{q}_{\mathrm{t}}=0$ at $\mathrm{t}=0$ and $\mathrm{q}_{\mathrm{t}}=\mathrm{q}_{\mathrm{t}}$ at $\mathrm{t}=\mathrm{t}$, that manifest Eq. (12)

$$
\begin{aligned}
& \frac{d q_{t}}{d t}=k_{1}\left(q_{e}-q_{t}\right) \\
& \ln \left(q_{e}-q_{t}\right)=\ln q_{e}-k_{1} t
\end{aligned}
$$

where $\mathrm{q}_{\mathrm{t}}$ represents the quantity $\left(\mathrm{mg} \mathrm{g}^{-1}\right.$ ) of adsorbate at time $\mathrm{t}(\mathrm{min})$ and $\mathrm{k}_{1}$ is the rate constant $\left(\mathrm{min}^{-1}\right)$. The rate constant was evaluated by plotting out slope of $\ln$ $\left(q_{\mathrm{e}}-q_{\mathrm{t}}\right)$ versus time ( $\left.\mathrm{t}\right)$ as shown in Fig. 6a. It is noted from the results in Table 2 that pseudo first order is

\begin{tabular}{|c|c|c|c|c|c|c|}
\hline \multirow{2}{*}{$\begin{array}{l}\text { Initial } \\
\text { Concentration } \\
\left(\mathrm{mg} \mathrm{L}^{-1}\right) \\
\end{array}$} & \multicolumn{3}{|c|}{ Pseudo First Order } & \multicolumn{3}{|c|}{ Pseudo Second Order } \\
\hline & $\overline{q_{e}\left(m g g^{-1}\right)}$ & $k_{1}\left(\min ^{-1}\right)$ & $\mathrm{R}^{2}$ & qe $\left(\mathrm{mg} \mathrm{g}^{-1}\right)$ & $\mathrm{k}_{2}\left(\mathrm{~g}^{-1} \mathrm{mg} \min \right)$ & $R^{2}$ \\
\hline 40 & 1.15 & 0.10 & 0.856 & 8.06 & 0.13 & 0.993 \\
\hline 60 & 1.35 & 0.30 & 0.812 & 12.0 & 0.083 & 0.99 \\
\hline 80 & 1.29 & 0.25 & 0.839 & 15.9 & 0.063 & 0.988 \\
\hline 100 & 1.39 & 0.33 & 0.806 & 20.0 & 0.051 & 0.984 \\
\hline 120 & 1.52 & 0.42 & 0.910 & 19.6 & 0.051 & 0.994 \\
\hline
\end{tabular}

Table 2 Adsorption parameters of kinetic models for pseudo first order and pseudo second order for the adsorption of RB-21 onto MMCC 
not in accordance with the adsorptive efficiency and the correlation coefficient value is lower. Thus, the adsorption of RB-21 onto MMCC fails to obey pseudo first order kinetics.

\section{Pseudo-second order model}

Pseudo-second order kinetic was calculated from Eq. (13) which after integrating gives Eq. (14) at the borderline of $\mathrm{qt}=0$ at $\mathrm{t}=0$ and $\mathrm{qt}=\mathrm{qt}$ at $\mathrm{t}=\mathrm{t}$, reordering to a linear pattern is given by Eq. (14)

$$
\begin{aligned}
& \frac{d q_{t}}{d t}=k_{2}\left(q_{e}-q_{t}\right)^{2} \\
& \frac{t}{q_{t}}=\left(\frac{1}{k_{2}} q_{e}^{2}+\frac{1}{q_{e}}\right) t
\end{aligned}
$$

where, $\mathrm{k}_{2}$ is the rate constant $\left(\mathrm{g}^{-1} \mathrm{mg} \mathrm{min}\right)$. The value of $k_{2}$ and $q_{e}$ were enumerated from the intercept and $t / q_{t}$ versus $t$ represents the slope, as shown in Fig. $6 \mathrm{~b}$.

The $k_{2}$ and $R^{2}$ of the above two kinetic models are shown in Table 2. It clearly indicated from the results, that pseudo second-order kinetic model represented $R^{2}>0.99$ for all the given concentrations and the rate constants value were lower with increase in the initial concentration of dye. The $\mathrm{q}_{\mathrm{e}}$ was found to increase from 8 to $20 \mathrm{mg} \mathrm{g}^{-1}$, with increasing initial dye concentrations ranging from 40 to $120 \mathrm{mg} \mathrm{L}^{-1}$. The high values of $\mathrm{R}^{2}>0.99$ suggest a better fit of data with a pseudo-second-order kinetic model.

\section{Conclusions}

The study validates that MMCC is an efficient and excellent adsorbent for decolourisation of RB-21 dye from the aqueous solution and the adsorption was accomplished in $50 \mathrm{~min}$. The optimum adsorption was achieved at $0.25 \mathrm{~g}$ catalyst, for $50 \mathrm{~min}$ with adsorption capacity of $30 \mathrm{mg} \mathrm{g}^{-1}$ at $323 \mathrm{~K}$ at $\mathrm{pH} 2$. The adsorption isotherm of Langmuir model offered a better fit of the data. The thermodynamic parameters were evaluated at different temperature with $\Delta \mathrm{S}^{\circ}$ found to be $0.47 \mathrm{~kJ} \mathrm{~mol}^{-1} \mathrm{k}^{-1}$. The pseudo second order model was better fit to the well observed adsorption data. The superior adsorption capacity of RB-21 using MMCC signifies wide applicability of dye removal in various textile industries.

\section{Acknowledgments}

The researchers would like to acknowledge the facilities made available by the DST, Govt of India through FIST and World Bank funded TEQIP-II in completing this research project.

\section{Authors' contributions}

All authors read and approved the final manuscript.

\section{Competing interests}

The authors declare that they have no competing interests.

\section{Publisher's Note}

Springer Nature remains neutral with regard to jurisdictional claims in published maps and institutional affiliations.

Received: 18 April 2018 Accepted: 14 January 2019

Published online: 03 April 2019

\section{References}

1. Saxena A, Bhardwaj M, Allen T, Kumar S, Sahney R. Adsorption of heavy metals from wastewater using agricultural-industrial wastes as biosorbents. Water Sci. 2017:31:189-97.

2. Asfaram A, Ghaedi M, Dashtian K, Ghezelbash GR. Preparation and characterization of $\mathrm{Mn}_{0.4} \mathrm{Zn}_{0.6} \mathrm{Fe}_{2} \mathrm{O}_{4}$ nanoparticles supported on dead cells of Yarrowia lipolytica as a novel and efficient adsorbent/biosorbent composite for the removal of azo food dyes: central composite design optimization study. ACS Sustain Chem Eng. 2018;6:4549-63.

3. Mazaheri H, Ghaedi M, Azqhandi MHA, Asfaram A. Application of machine/ statistical learning, artificial intelligence and statistical experimental design for the modeling and optimization of methylene blue and cd(II) removal from a binary aqueous solution by natural walnut carbon. Phys Chem Chem Phys. 2017;19:11299-317.

4. Tünay O, Kabdasli I, Eremektar G, Orhon D. Color removal from textile wastewaters. Water Sci Technol. 1996;34:9-16.

5. Ansari F, Ghaedi M, Taghdiri M, Asfaram A. Application of $\mathrm{ZnO}$ nanorods loaded on activated carbon for ultrasonic assisted dyes removal: experimental design and derivative spectrophotometry method. Ultrason Sonochem. 2016;33:197-209.

6. Rajeshwarisivaraj SS, Senthilkumar P, Subburam V. Carbon from cassava peel, an agricultural waste, as an adsorbent in the removal of dyes and metal ions from aqueous solution. Bioresour Technol. 2001;80:233-5.

7. Senthilkumaar S, Varadarajan PR, Porkodi K, Subbhuraam CV. Adsorption of methylene blue onto jute fiber carbon: kinetics and equilibrium studies. J Colloid Interface Sci. 2005;284:78-82.

8. Fu ZM, Zhang YG, Wang XJ. Textiles wastewater treatment using anoxic filter bed and biological wriggle bed-ozone biological aerated filter. Bioresour Technol. 2011;102:3748-53.

9. Gupta VK, Jain R, Varshney S. Removal of Reactofix golden yellow 3 RFN from aqueous solution using wheat husk- an agricultural waste. J Hazard Mater. 2007;142:443-8.

10. Roosta M, Ghaedi M, Asfaram A. Simultaneous ultrasonic-assisted removal of malachite green and safranin $\mathrm{O}$ by copper nanowires loaded on activated carbon: central composite design optimization. RSC Adv. 2015;5:57021-9.

11. Bagheri AR, Ghaedi M, Asfaram A, Bazrafshan AA, Jannesar R. Comparative study on ultrasonic assisted adsorption of dyes from single system onto $\mathrm{Fe}_{3} \mathrm{O}_{4}$ magnetite nanoparticles loaded on activated carbon: experimental design methodology. Ultrason Sonochem. 2017;34:294-304.

12. Bozlur RM, Shibata S, Diba CSF, Uono M. Low cost biodegradable adsorbent material for the removal of dissolved dyes from aqueous solutions: an economical process. IACSIT Int J Eng Technol. 2010;2:468-73.

13. Díaz AB, Blandino A, Belleli C, Caro I. An effective process for pretreating rice husk to enhance enzyme hydrolysis. Ind Eng Chem Res. 2014;53:10870-5.

14. Mafra MR, Igarashi-Mafra L, Zuim DR, Vasques ÉC, Ferreira MA. Adsorption of Remazol brilliant blue on an orange peel adsorbent. Braz J Chem Eng. 2013:30:657-65.

15. Ghaedi M, Rozkhoosh Z, Asfaram A, Mirtamizdoust B, Mahmoudi Z, Bazrafshan AA. Comparative studies on removal of erythrosine using ZnS and $\mathrm{AgOH}$ nanoparticles loaded on activated carbon as adsorbents: kinetic and isotherm studies of adsorption. Spectrochim Acta A. 2015;138:176-86.

16. Silva LS, Lima LCB, Silva FC, Matos JME, Santos MRMC, Santos LS, et al. Dye anionic sorption in aqueous solution onto a cellulose surface chemically modified with aminoethanethiol. Chem Eng J. 2013;218:89-98.

17. da Silva EC, de Melo JCP, Airoldi C. Preparation of ethylenediamineanchored cellulose and determination of thermochemical data for the interaction between cations and basic centers at the solid/liquid interface. Carbohydr Res. 2006;341:2842-50.

18. Asfaram A, Ghaedi M, Yousefi F, Dastkhoon M. Experimental design and modeling of ultrasound assisted simultaneous adsorption of cationic dyes onto ZnS: Mn-NPs-AC from binary mixture. Ultrason Sonochem. 2016;33:77-89.

19. Bezerra RDS, Leal RC, da Silva MS, Morais AIS, Marques THC, Osajima JA, et al. Direct modification of microcrystalline cellulose with ethylenediamine for 
use as adsorbent for removal amitriptyline drug from environment. Molecules. 2017;22:2039.

20. Bezerra RDS, Morais AIS, Osajima JA, Nunes LCC, Silva Filho EC. Cellulose phosphate applied in the removal of the drug acetaminophen from aqueous media. Mater Sci Forum. 2016;869:745-9.

21. Hashem A, El-Shishtawy RM. Preparation and characterization of cationized cellulose for the removal of anionic dyes. Adsorpt Sci Technol. 2001;19:197-210.

22. Ahmad AA, Hameed BH, Aziz N. Adsorption of direct dye on palm ash: kinetic and equilibrium modeling. J Hazard Mater. 2007;141:70-6.

23. Qi Y, Li J, Wang LJ. Removal of Remazol turquoise blue G-133 from aqueous medium using functionalized cellulose from recycled newspaper fiber. Ind Crop Prod. 2013;50:15-22.

24. Abdelmouleh M, Boufi S, ben Salah A, Belgacem MN, Gandini A. Interaction of silane coupling agents with cellulose. Langmuir. 2002;18:3203-8.

25. Aroguz AZ, Gulen J, Evers RH. Adsorption of methylene blue from aqueous solution on pyrolyzed petrified sediment. Bioresour Technol. 2008;99:1503-8.

26. Sheltami RM, Kargarzadeh $\mathrm{H}$, Abdullah I. Effects of silane surface treatment of cellulose nanocrystals on the tensile properties of cellulose-polyvinyl chloride nanocomposite. Sains Malays. 2015;44:801-10.

27. Franklin DS, Guhanathan S. Substantial performance of silane surface treated 1, 4 butane diol/hydroxyapatite biocomposite hydrogels for dye removal applications. Am J Chem Mater Sci. 2015;1:24-9.

28. Lu J, Askeland P, Drzal LT. Surface modification of microfibrillated cellulose for epoxy composite applications. Polymer. 2008:49:1285-96.

29. Cabuk M, Alan Y, Unal HI. Enhanced electrokinetic properties and antimicrobial activities of biodegradable chitosan/organo-bentonite composites. Carbohyd Polym. 2017;161:71-81.

30. Isah U, Abdulraheem G, Sala S, Muhammad S, Abdullahi M. Kinetics, equilibrium and thermodynamics studies of C.I. Reactive blue 19 dye adsorption on coconut shell based activated carbon. Int Biodeter Biodegr. 2015;102:265-73.

31. Sarkar K, Banerjee SL, Kundu PP. Removal of anionic dye in acid solution by self crosslinked insoluble dendronized chitosan. Hydrol Current Res. 2012;3:133.

32. Adewuyi A, Pereira FV. Preparation and application of EDTA-functionalized underutilized Adansonia digitata seed for removal of $\mathrm{cu}(\mathrm{II})$ from aqueous solution. Sustain Environ Res. 2018;28:111-20.

33. Cabuk M. Electrorheological properties of biodegradable chitosan/expanded perlite composites. J Turk Chem Soc. 2016;3:119-32.

34. Banerjee $\mathrm{S}$, Chattopadhyaya MC. Adsorption characteristics for the removal of a toxic dye, tartrazine from aqueous solutions by a low cost agricultural by-product. Arab J Chem. 2017;10:S1629-38.

35. Newcombe G, Drikas M. Adsorption of NOM onto activated carbon: electrostatic and non-electrostatic effects. Carbon. 1997;35:1239-50.

36. Hema M, Arivoli S. Comparative study on the adsorption kinetics and thermodynamics of dyes onto acid activated low cost carbon. Int J Phys Sci. 2007;2:10-7.

37. Dahri MK, Kooh MRR, Lim LBL. Water remediation using low cost adsorbent walnut shell for removal of malachite green: equilibrium, kinetics, thermodynamic and regeneration studies. J Environ Chem Eng. 2014:2:1434-44

38. Vijayakumar G, Tamilarasan R, Dharmendirakumar M. Adsorption, kinetic , equilibrium and thermodynamic studies on the removal of basic dye rhodamine-B from aqueous solution by the use of natural adsorbent perlite. J Mater Environ Sci. 2012;3:157-70.

\section{Ready to submit your research? Choose BMC and benefit from:}

- fast, convenient online submission

- thorough peer review by experienced researchers in your field

- rapid publication on acceptance

- support for research data, including large and complex data types

- gold Open Access which fosters wider collaboration and increased citations

- maximum visibility for your research: over $100 \mathrm{M}$ website views per year

At $\mathrm{BMC}$, research is always in progress.

Learn more biomedcentral.com/submissions 